Conclusions: The IGU therapy improved not only the disease activity not also the inflammatory synovitis. The present study provides evidence supporting the improvement of GS and PD score from baseline to week24 may predict whether the achieved remission or not at Week 52 .

Disclosure of Interest: None declared

DOI: 10.1136/annrheumdis-2017-eular.6948

\section{THU0213 COMPARATIVE EFFICACY AND SAFETY OF BARICITINIB 2 MG AND 4 MG IN PATIENTS WITH ACTIVE RHEUMATOID ARTHRITIS: A BAYESIAN NETWORK META-ANALYSIS OF RANDOMIZED CONTROLLED TRIALS}

Y.H. Lee, Y.H. Seo, G.G. Song. Rheumatology, Korea University Medicial Center, Seoul, Korea, Republic Of

Background: Baricitinib is a potent, selective JAK1 and JAK2 inhibitor. Baricitinib has been investigated in phase II and phase III studies of active patients with rheumatoid arthritis (RA). who showed an inadequate response to diseasemodifying antirheumatic drugs (DMARDs), including methotrexate (MTX) and biologics. However, due to the lack of adequate multiple comparisons, the comparative efficacy and safety of baricitinib in various treatment regimens with different dosages or in combination with DMARDs or MTX remains unclear. Objectives: This study aimed to assess the relative efficacy and safety of once-daily baricitinib $2 \mathrm{mg}$ and $4 \mathrm{mg}$ administration in patients with active RA. Methods: We performed a literature search using MEDLINE, EMBASE, the Cochrane Controlled Trials Register, and the EULAR and ACR conference proceedings. In this network meta-analysis, randomized controlled trials (RCTs) examining the efficacy and safety of baricitinib in patients with active RA were included. A Bayesian network meta-analysis was conducted to combine the direct and indirect evidence from the RCTs.

Results: Seven RCTs involving 3,461 patients met the inclusion criteria. There were 10 pairwise comparisons, including 7 direct comparisons and 5 interventions. The ACR20 response rate was significantly higher in the baricitinib $4 \mathrm{mg}$ in combination with disease-modifying antirheumatic drugs (DMARD) group than in the placebo+DMARD group (OR 3.13,95\% Crl 2.32-4.33). Compared with the placebo+DMARD group, the baricitinib $4 \mathrm{mg}$, baricitinib $2 \mathrm{mg}+\mathrm{DMARD}$, and adalimumab $40 \mathrm{mg}+\mathrm{MTX}$ groups showed a significantly higher ACR20 response rate. The ranking probability based on the surface under the cumulative ranking curve (SUCRA) indicated that baricitinib $4 \mathrm{mg}+\mathrm{DMARD}$ was likely to elicit the best ACR20 response rate (SUCRA $=0.7930$ ), followed by baricitinib $4 \mathrm{mg}$ (SUCRA $=0.7034)$, baricitinib $2 \mathrm{mg}+$ DMARD (SUCRA $=0.6304)$, adalimumab $40 \mathrm{mg}+\mathrm{MTX}$ (SUCRA $=0.3687$ ), and placebo+DMARD (SUCRA $=0.0045)$. By contrast, the safety based on the number of treatment-emergent adverse events (TEAEs) did not differ significantly among the 5 interventions.

Conclusions: Baricitinib $2 \mathrm{mg}$ and $4 \mathrm{mg}$ administered once daily was an efficacious intervention for active RA that had no significant risk of TEAE development.

Acknowledgements: None

Disclosure of Interest: None declared

DOI: 10.1136/annrheumdis-2017-eular.1245

\section{THU0214 LONG-TERM OUTCOME OF IGURATIMOD, CONVENTIONAL SYNTHETIC DISEASE-MODIFYNG ANTI-RHEUMATIC DRUD DEVELOPED IN JAPAN, IN JAPANESE PATIENTS WITH RHEUMATOID ARTHRITIS IN REAL-WORLD CLINICAL SETTING}

Y. Hirano, M. Isono, Y. Okada, Y. Oishi. Rheumatology, Toyohashi Municipal Hospital, Toyohashi, Japan

Background: Iguratimod (IGU) is csDMARDs developed in Japan and used in Japanese daily practice since 2012. Although IGU was developed as an anti-inflammatory drug at first, anti-rheumatic effect was found in experiments using type II collagen-induced arthritis model mice ${ }^{1)}$. Main mode of action of IGU was thought to be inhibition of NF-kB resulted in decreased production of IL-6, IL-8 and TNF-alpha ${ }^{2}$. Clinical trials performed in Japan showed that efficacy of IGU was equal to sulfasalazine when used as monotherapy in patients with rheumatoid arthritis (RA) ${ }^{3)}$. Additive efficacy to MTX was also shown in double-blind randomised trial in RA patients ${ }^{4}$ ). Although several short-term results were published ${ }^{5}$, long-term results in daily clinical setting is lacking.

Objectives: To investigate long-term outcome of IGU in patients with RA.

Methods: 120 RA patients treated with IGU in our institute from April 2013 to June 2016 were included. Patients' characteristics, factors influencing to prescribing of IGU (why was IGU chosen as treating csDMARDs?), drug continuation rates (Kaplan-Meier) were investigated. Time course of disease activity (DAS28-CRP \& SDAl) was also investigated using 65 cases who passed 2 years after starting of IGU.

Results: Baseline characteristics was as below. Mean age was 64.9 years old, \%female was $74.2 \%$, mean RA duration was 10.0 years and MTX was concomitant in $50.0 \%$ of cases. $82 \%$ of patients had factors influencing to prescribing IGU and intolerance of dose escalation of MTX was 1 st reason (23.3\%), old age over 80 years old was 2 nd reason (16.7\%) and economical reason was 3rd (14.2\%) (Table1). Drug continuation rates were $71.1 \%$ at 1 year, $48.9 \%$ at 2 years and
$43.1 \%$ at 3 years (Fig1). Time course of disease activity (baseline- 6 months-1 year-2 year) was 3.6-3.0-3.0-3.0 in DAS28-CRP. In 15 cases in remission of DAS28-CRP at 2 years, 2 were classified with high disease activity and 9 were moderate disease activity at baseline (Fig2).

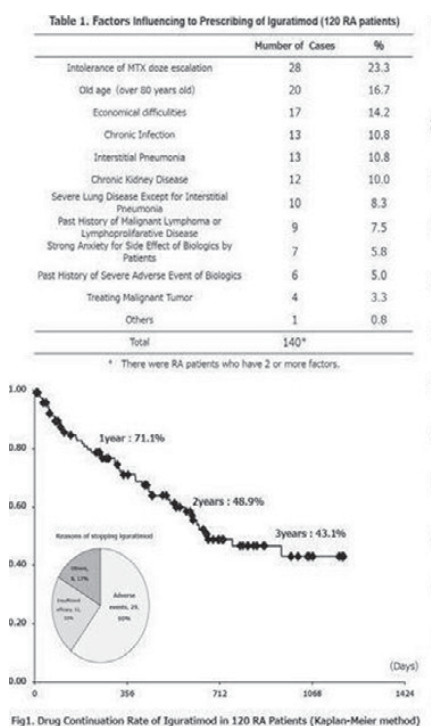

[DAS28-CRP Category (n=65) ] [SDAI Category (n=65)]

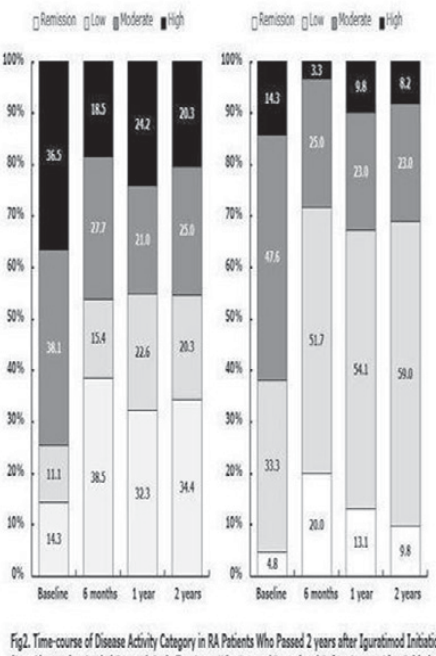

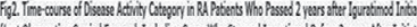

Conclusions: Efficacy of IGU in RA patients who had intolerance of MTX dose escalation or usage of biologics was observed. Although biological DMARDs is effective in RA patients, the cost is very expensive. IGU is comparative cheap ( $¥ 9,200 /$ month) and suitable for RA patients with economical difficulties. As IGU decreased TNF-alpha production via inhibition of NF-kB, MTX+IGU may have similar mode of action with MTX+TNF inhibitor. Drug continuation rates were decreased over time and escape of efficacy may occur in some patients. Otherwise, IGU was very effective in some cases. Some of RA patients with high disease activity decreased disease activity greatly to remission state at 2 years after initiation of IGU.

References:

[1] Aikawa et al. Inflamm res. 51; 188-194 2002.

[2] Kohno et al. J Rheumatol. 28; 2591-2596 2001.

[3] Hara et al. Mod Rheumatol. 17; 1-9 2007

[4] Ishiguro et al. Mod Rheumatol. 23; 430-439 2013.

[5] Yoshioka et al. Mod Rheumatol. 26; 169-174 2016.

Disclosure of Interest: None declared

DOI: 10.1136/annrheumdis-2017-eular.4852

\section{THU0215 EFFECTS OF TOFACITINIB ON PATIENT-REPORTED OUTCOMES IN A PHASE 3 STUDY OF CHINESE PATIENTS WITH ACTIVE RHEUMATOID ARTHRITIS AND AN INADEQUATE RESPONSE TO DMARDS}

Z. $\mathrm{Li}^{1}, \mathrm{Y} . \mathrm{An}{ }^{1}, \mathrm{G} . \mathrm{Li}^{2}, \mathrm{~L}$. Wang ${ }^{3}, \mathrm{~K} . \mathrm{Kwok}^{4}, \mathrm{Q}$. Wu ${ }^{2}$ on behalf of China ORAL group. ' 1 Peking University People's Hospital; ${ }^{2}$ Pfizer Inc, Beijing, China; ${ }^{3}$ Pfizer Inc, Groton, CT; ${ }^{4}$ Pfizer Inc, New York, NY, United States

Background: Rheumatoid arthritis (RA) worsens patients' health-related quality of life. ${ }^{1}$ Tofacitinib is an oral Janus kinase (JAK) inhibitor for the treatment of RA Improvements in patient-reported outcomes (PROs) have been reported in the global population of Phase 3 tofacitinib trials. ${ }^{2}$

Objectives: To explore the effect of tofacitinib administered with conventional synthetic DMARDs (csDMARDs) on PROs in Chinese patients with RA and an inadequate response to DMARDs.

Methods: This was a post-hoc analysis of data from Chinese patients in the 12 month, double-blind Phase 3 study ORAL Sync (NCT00856544), with patients randomised $4: 4: 1: 1$ to tofacitinib $5 \mathrm{mg}$ BID, tofacitinib $10 \mathrm{mg} \mathrm{BID}$, placebo (PBO) $\rightarrow$ tofacitinib $5 \mathrm{mg}$ BID or PBO $\rightarrow$ tofacitinib $10 \mathrm{mg}$ BID, with csDMARDs. Non-responders (defined as those who did not achieve a $20 \%$ improvement in both of the swollen or tender joint counts) receiving PBO advanced blindly to tofacitinib at Month 3; all remaining PBO patients advanced to tofacitinib at Month 6. Least squares mean changes from baseline were reported for Health Assessment Questionnaire-Disability Index (HAQ-DI), patient assessment of arthritis pain (VAS), patient global assessment of disease activity (PtGA), Functional Assessment of Chronic Illness Therapy (FACIT) Fatigue scale, Short Form-36 Health Survey (SF-36), EuroQol five dimensions questionnaire (EQ-5D), and Work Limitations Questionnaire (WLQ), using a mixed-effects model for repeated measures. All patients receiving $\geq 1$ dose of study treatment with $\geq 1$ post-baseline assessment were included.

Results: Overall 216 patients were included ( $n=86$, tofacitinib $5 \mathrm{mg} \mathrm{BID;} n=86$, tofacitinib $10 \mathrm{mg} \mathrm{BID} ; \mathrm{n}=22, \mathrm{PBO} \rightarrow$ tofacitinib $5 \mathrm{mg} \mathrm{BID} ; n=22, \mathrm{PBO} \rightarrow$ tofacitinib 